\title{
Come Early, Stay a While
}

\section{The 2005 SRM Planning Committee offers a variety of events to enjoy and chances to explore when you visit Fort Worth, Texas next February for the $\mathbf{5 8}^{\text {th }}$ Annual Meeting of the Society for Range Management.}

\author{
By Ellen Humphries
}

V isitors to Fort Worth, Texas, for the February 2005 Society for Range Management Annual Meeting and Trade Show will have ample opportunity to explore and learn about the culture and resources of North Texas.

Tours, workshops and sessions will explore the varied trails found in rangeland management - both traditional and non-traditional - and how we travel along those trails.

Additional events are designed to give up-andcoming range resource managers plenty of time to interact with the professionals.

\section{Pre-Conference Workshops - February 5-6}

While Fort Worth is part of the North Texas metroplex, it remains a ranching community which values its heritage. Program planners will capitalize on this mix by offering a variety of pre-conference workshops geared for the general public and rural landowners.

"Partners on the River and the Range," a workshop to be conducted by the Texas Rivers Association, will demonstrate the partnership approach toward managing Texas' rivers. The Texas Prairie Rivers program combines traditional range improvement concerns with habitat conservation and improvement, while reaching out to the urban public through nature-based tourism activities.

The innovative Leon River Restoration Project will be discussed at another workshop. Success in this large-scale restoration project was achieved through an unprecedented public-private partner- ship on land used for military training maneuvers. This will be an interesting discussion on balancing the needs of cattle, wildlife and armored personnel carriers.

Those with an interest in ranching - either to start up or to brush up - are invited to attend workshops on the basics of ranching; risk management and ranch economics; do-it-yourself brush control; and land protection through conservation easements. There will also be a session on managing wildlife in North Texas' post oak savannah ecosystem.

The general public might find interest in the workshop on identifying and using Texas rangeland plants in the urban and suburban landscape. Along with significant water savings, landscapes with native and naturalized plants help the landowner avoid the humdrum "Anyplace USA" yard and help attract area wildlife such as birds.

Speaking of which, bird watching is an increasingly popular hobby and avocation everywhere. The Audubon Society is partnering with us to provide a workshop on the diversity of Texas' rangeland birds.

\section{Cultural and Western Heritage Tours - February 8 and 11}

Fort Worth is a museum city. Two tours are being offered to explore the culture and heritage presented by these excellent facilities. On Tuesday, February 8 , the Cultural Tour will take guests through Thistle Hill, one of the few remaining cattle baron mansions, and to the Amon Carter and Kimbell Art Museums.

The Amon Carter Museum was established by 
Amon Carter Sr. to house his collection of paintings and sculpture by Frederic Remington and Charles M. Russell, who painted "The Trail Boss." It has developed into one of the finest displays of American art in the country. The Kimbell brings masterful collections from around the world to Fort Worth and maintains permanent displays which include works of antiquities; European and Asian art; and Pre-Columbian and African/Oceanic artifacts.

Food lovers will want to be part of this tour for the luncheon alone, which will be served at Michael's Restaurant and Ancho Chile Bar. Chef Michael Thompson is known for innovative cuisine such as Pepper-Crusted, Pan-Seared Tenderloin with Ancho Bourbon Sauce; Chicken-fried Flat Iron Steak; Pecan-Crusted Goat Cheese Chicken; Chipotle Chile Mashed Potatoes; and Mom's Banana Pudding.

On Thursday, February 11, the Western Heritage Tour will take guests to the Texas and Southwestern Cattle Raisers Museum. The tour will continue at the National Cowgirl Hall of Fame, where the theme is women "who have carved a path or paved the road for all women in many different walks of life."

Then guests will be turned loose to wander and shop in the historic Stockyards on the north side of Fort Worth. Shop at M.L. Leddy's Boot \& Saddlery, enjoy a beverage at the Stockyards Hotel and Saloon, have lunch or dinner at the Cattleman's Steakhouse, and enjoy live music at the White Elephant Saloon, or catch the latest Country/Western singer at Billy Bob's.

Be on Exchange Avenue about 4:00 p.m. to see the cowboys drive the Fort Worth herd of Longhorn steers up the avenue to illustrate the early days when the Fort Worth Stockyard was a primary destination along the trails under the Lone Star.

\section{Technical Tours - February 5, 8 and 10}

Even the technical tours are shaping up to be fun. Start out with the day-long "Ranching on the Grand Prairie of Texas," where you'll visit two of central Texas' finest ranches.

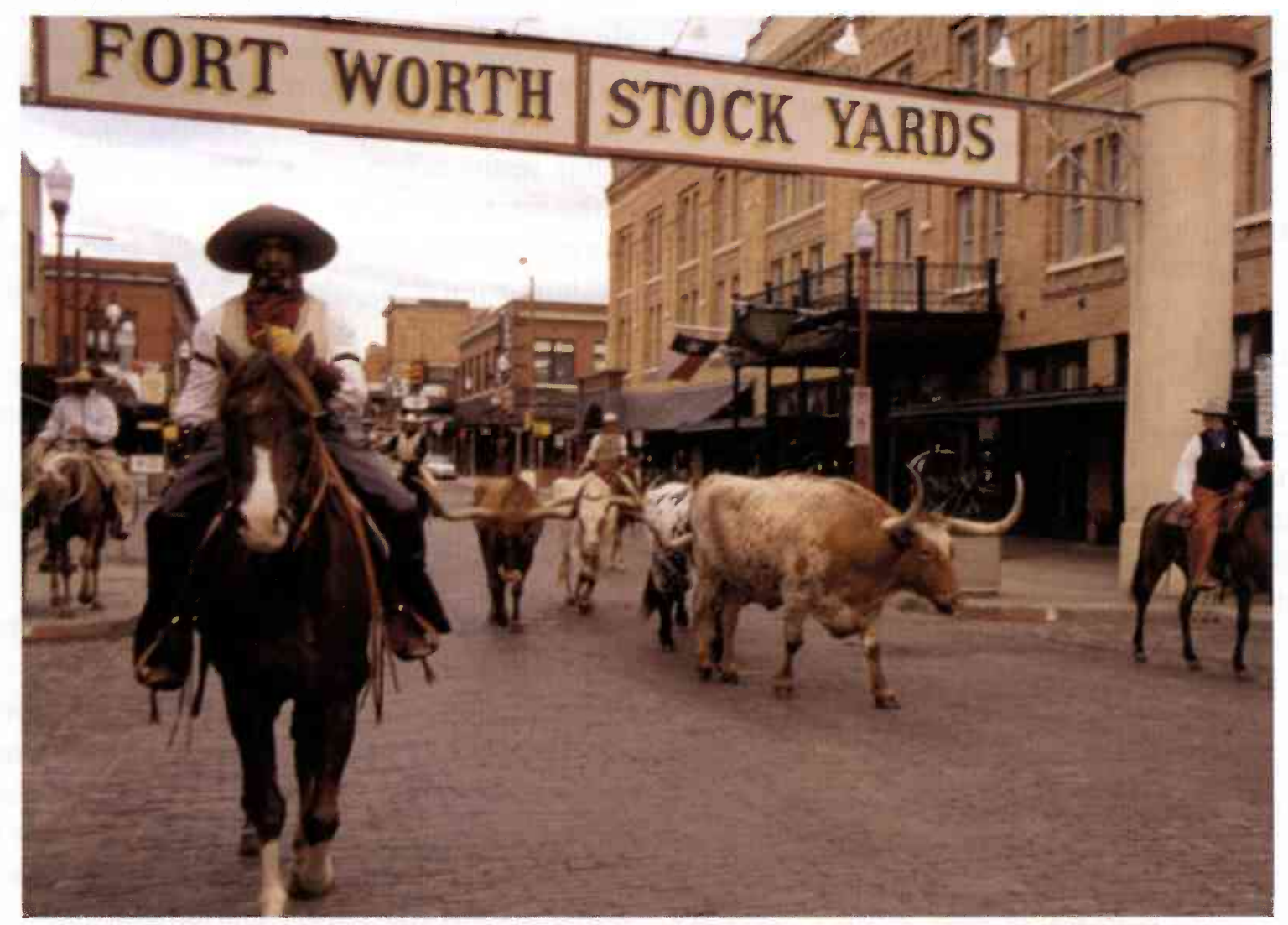

Be on Exchange Avenue about 4:00 p.m. to see the cowboys drive the Fort Worth herd of longhorn steers up the avenue to the Fort Worth Stockyards. 
The Winscott Ranch, about 20 miles southwest of Fort Worth, has traditionally been a stocker steer operation. Prescribed fire, weed and brush control and grazing management techniques have been used to improve profitability. The ranch owners have integrated livestock management and technology to overcome adverse weather conditions and fluctuating livestock numbers.

Following a catered lunch, we will head for the Little Hoss Ranch, on which the owners have changed their emphasis from cow-calf production to white-tailed deer, Rio Grande turkey and bobwhite quail management. Visitors will see how prescribed fire and other wildlife management techniques are used to improve the quality of the native habitat for those species and improve the range condition of the ranch.

A half-day, tour has been scheduled for the Botanical Research Institute of Texas (BRIT). BRIT holds in public trust a herbarium of about one million specimens representing more than 90 percent of the world's plant families. Its botanical reference library, containing more than 75,000 volumes of books and journals, some very old and rare, is one of the largest and finest collections of botanical literature in the Southwestern United States.

Details are still being hammered out for a third tour to explore non-traditional uses of rangeland and to visit the LBJ National Grasslands at Decatur, Texas, north of Fort Worth.

\section{Annual Meeting - February 6 through 11 "Rangeland Trails under the Lone Star" will be explored in a multitude of presentations, technical sessions and symposia at the 2005 meeting.}

Program Committee Co-Chair Urs Krueter, explains, "Trails lead in many directions and cross at many points to form an intricate and expanding network of knowledge about rangelands. The technical sessions and symposia will focus on the interaction of diverse disciplines and issues relevant for the management of rangeland resources."

Papers and symposia will address these broad areas:

- Contemporary issues

- Ecology and ecosystem interactions

- Ecosystem health, monitoring and methodologies

- Natural resource management

- Animal production systems

- Socio-economics of the rangeland

\section{Activities for the Young}

Young folks add a lively spirit to any meeting and we encourage students to attend the 2005 conference. A High School Youth Forum Resource Tour is being developed as part of the youth activities.

Planners are developing a program tailored to college undergraduate and graduate students, while allowing plenty of time for students to interact with professionals.

"Rangeland Trails Under The Lone Star" will celebrate and explore the layers of culture, history and natural heritage supported by rangelands. Take advantage of these unique tours and opportunities to explore when you plan your travels to Fort Worth next year. For more details throughout 2004, be sure to check our Web site at www.tssrm.org.

Come early and stay a while. 